\title{
DIGITAL DESIGN OF PRODUCTION SYSTEMS USING VIRTUAL REALITY Gabriela Gabajová ${ }^{1}$, Martin Krajčovič르, Iveta Rolinčinová ${ }^{3}$, Beáta Furmannová ${ }^{4}$, Monika Bučková ${ }^{5}$
}

\begin{abstract}
The design and operation of intelligent production and logistics systems requires the strong support of digital technologies today. A production and logistics system is normally modelled in a virtual environment, allowing rapid work with an extensive data set and "what - if" analyses to help optimize the resulting system design for performance, productivity, safety and environmental performance of its future operation. This paper deals with the issue of the digital design of production systems with the effective deployment of virtual reality technologies into the individual phases of the production system design. This article describes the basic steps of the digital design methodology with the description of virtual reality application tools for the production and logistics system design, in order to reduce design defects and increase work safety. The proposed methodology has been verified in an experimental workplace, presenting real outputs. The final part of the article contains a brief discussion of the problem results.
\end{abstract}

JEL Classification Numbers: L23, L52, DOI: https://doi.org/10.12955/peb.v1.18

Keywords: production, designing, virtual reality, productivity, immersive technologies.

\section{Introduction}

Business environments are constantly changing today. There are great requirements of current business systems due to the continuously increasing customer requirements of product quality and innovation as well as the constant acceleration of technological development. The economy is influenced by customer behavior not only by its cycles (Gregor, 2015). The process of designing production systems must quickly adapt to customer requirements (Mičieta, 2018). Modern production and logistic system designers try to implement quick adaptation to changing market conditions, autonomous decisionmaking, self-organisation and self-optimisation of production and logistic processes with consideration for their safety (Kovalský, 2017). Nowadays, these systems are called intelligent systems. They use new technology types to collect, process and use information from processes. The intelligent logistic and production systems represent part of the new Industry 4.0 concept and are a core feature of future intelligent plants. Intelligent production and logistic system design requires the application of digital technologies into the entire cycle of the production system. The concept of using the software environment to design, plan and manage company processes and systems in the virtual environment is called a digital company. A digital company involves digitisation and coherence of the three most significant company information fields: the product, process information and company sources. Production and logistic system design are one of the most basic activities in the digital company concept. Its main task is to access relations among individual production system elements in terms of time and space requirements for work, technological, manipulation, control and other activities inevitable to the implementation of rational production processes and the relevant space and time structures of the production process. Quick company innovations put pressure on the increased requirements of production and logistic system design from the point of view of labour intensity, time consumption and implementation costs of the entire technological design process. Also, due to the reason of quality increase, complexity and ability of design outputs generated from this process. Therefore, the following basic requirements of technological design process could be summed up:

- a quick proposal of new solutions,

- system access compliance when designing,

- production system design being part of the digital company concept,

- an interaction proposal of the new production / logistic system,

\footnotetext{
${ }^{1}$ University of Žilina, Faculty of Mechanical Engineerig, Department of Industrial Engineering, email: gabriela.gabajova@fstroj.uniza.sk.

${ }^{2}$ University of Žilina, Faculty of Mechanical Engineerig, Department of Industrial Engineering, email: martin.krajcovic@fstroj.uniza.sk.

${ }^{3}$ University of Žilina, Faculty of Mechanical Engineerig, Department of Industrial Engineering, email: iveta.rolincinova@fstroj.uniza.sk.

${ }^{4}$ University of Žilina, Faculty of Mechanical Engineerig, Department of Industrial Engineering, email: beata.furmannova@fstroj.uniza.sk.

${ }^{5}$ University of Žilina, Faculty of Mechanical Engineerig, Department of Industrial Engineering, email: monika.buckova@fstroj.uniza.sk.
} 
- the possibility of continuous check ups and evaluations of proposed solution options,

- the optimisation of the access application when designing the time and space sctructure of the production system,

- suitable visualisation and design output presentation,

- dynamic check-up of the proposed solution.

Fulfilment of the above mentioned requirements requires digital technology implementation into all phases of the production system. Technologies, such as reverse engineering, 3D modelling, interactive design, computer simulation and augmented reality are becoming standard tools supporting the digital design of production and logistic systems. There are various problems and risks that occur when designing production and logistic systems. It is the application of virtual and augmented reality applications which decreases these risks significantly, and more importantly it ensures the safety of future production systems. There have been many factory design or production system design materials published. The foundations of systematic design are described in Muther, R. (1973) publications or even in the extensive works of Aggeteleky, B. (1987), (1990). Schmigall, H. (1995) who are known for publishing work on factory design containing determining concepts and connections occuring when designing factories. Grundig, C.G. (2006) and Pawelek, G. (2008) are also known for works on factory design and production systems. Wiendahl, H. P. (2009) publishes an extensive Handbook on factory design containing many recommendations and instructions, grids and graphs used in practical design. Sule, D. R. (2009) describes the entire process of factory design including computer design of layout process. Kühn, W. (2006) publishes a series of works designed to use digital company technology when designing production systems. Dashchenko, O. (2006) publishes modern structures and trends when making a layout of future factories.

This work is focused on the development forecast in automobile production. One of the most significant and key topics when designing production systems in a digital company concept is the computer simulation of production and logistic systems with its roots in universities in the USA. The most significant authors are Pegden, C. D. (1995), Banks, J. (2005), Law, A.M. (1999, 2006) and Kelton, W.D. (2011). In addition, current factory design together with production and logistic system management requires better visualisation of each step and output of the decision-making process. This is the key potential for future virtual and augmented technology. Azuma (1997) describes the basic principles of augmented reality as one of the forms of mixed reality, combining the virtual and real world. Ong, S. K. and Nee, A. Y. C. (2004) describe practical examples of virtual and augmented reality in production. Khan, W. A. (2011) describes virtual production system, his basic components and technologies that he uses. Mihejl, M. (2014), describes the entire environment of virtual reality application from the basic characteristics of the virtual world, as well as, technical elements creating virtual environments (tracking systems, display and acustic systems, haptic elements, etc.). The complex and detailed principle and the technology description used in the field of augmented reality is described by Schmalstieg, D. a Hollerer, T. (2016). Ma, D. (2011) uses a specific virtual and augmented reality application in the industrial environment. The matter of production system design is one of the key research areas of authors from the Department of Industrial Engineering (University of Žilina). These authors have been working on the development of a scientific school from the field of digital design of production systems, and production and logistic systems with dynamic simulation. Moreover, there has been technology use of virtual and augmented reality in the design and management of production and logistic processes and design concept development for future intelligent factories and their requirements. One of the most basic works of production system design is the work of Košturiak, J. (2000), containing a more complex view on the production system design for the first time. Apart from their own design, these authors have been working on the production integration effect and a series of tools and techniques used in modern production system design. In the publication of Gregor, M. (2006) the main principles of the digital company have been worked out, using the most advanced digital technologies. Mleczko (2014) analyses Manufacturing documentation for high-variety products. Moreover, Gregor, M. (2016) has elaborated the issue of digitisation of large objects in detail, which is the key prerequisite for digital company technology application and virtual as well as augmented reality in production and logistic system design. Gašová, M. (2017) has dealt with ergonomy and production workplace design in her publication. Dulina, L'. and Bartánusová, M. (2014) have described the use of CAVE (Computer Assisted Virtual Environments) technologies in digital design. Nowadays, the workplace research activities of authors are primarily focused on digital design development depending on future factory 
requirements. One of the most progressive areas is the virtual reality application of technologies in digital design, which is the main topic of this article. The introduction of this article opens the topic of digital company concept and digital production system design, as well as most significant scientific sources published so far. Furtheremore, the main body of the article describes basic steps of digital design methodology, but it mainly describes virtual reality tool applications into manufacturing and logistic system design. The proposed methodology has been verified at experimental stations. This verification results in having realistic outputs. In conclusion of this article, a short results discussion of the issue is mentioned.

\section{Digital design of production system and its methodology}

Production and logistic system design in the digital company concept requires the implementation of several areas.

\section{Input data preparation and analysis}

The basic source of information necessary for design is mainly data from construction and technological production preparation. Data needed to design production disposition must contain product information, which will be produced in the production system (types of products, pieces, construction parameters, planned production volume, etc.), and sources, which will be used for their production (machines, equipment, tools, workers, transport, manipulation design, etc.).

\section{Production system capacity dimensioning and system design}

Objective capacity determination needed to secure the production process is an important part of a technological project. The result of production system capacity dimensioning is the determination of the needed machines, workers, transport and manipulation devices, the size and number of warehouses, production and auxiliary area, energies, etc. Knowledge of resources needed for individual categories together with planned material movements in the production represent a base when designing a production system solution. The main aim of the conceptual design is to design multiple variations of a production and logistic system, its mutual comparison and variation selection, which will be designed in detail with the use of digital design tools. The principal questions of the solution concept have been discussed, such as: production character, material flow, intercompany transport system, production system organisation and maanagement, production energy security, work and hygienic conditions, special company requirements, safety, etc.

\section{Digital design material preparation}

Design and visualisation of production and logistic system in the digital environment requires 3D model preparation for all components needed for the proposed system (production machines and equipment, transport and manipulation devices, manipulation units, storage facilities, auxiliary facilities, etc.) The created 3D digital models are then the main basis of production and logistic system digital design in a computer environment. One of the following procedures could be used when preparing 3D models of individual production and logistic system objects:

- a new model making use of CAD softwares (AutoCAD, Microstation, CATIA, etc.),

- a new 3D model obtained with use of reverse engineering methods (3D laser scanning),

- the production and use of 3D parametric models,

- adapting existing CAD model with the use of software tools for modelling, rendering and 3D model animating (Autodesk Maya, 3ds Max).

\section{$3 D$ model production system creation in the digital environment}

3D model creation consits of a final model assembly from individual objects representing individual elements of the production system (machines, areas, workers, storage facilities, manipulation units, etc.) These objects are spatially arranged within the selected production concept and all norm, directive and principle compliance of technological design. The final 3D model is a representation of a real production system in the digital environment. A 3D model is created in the selected scale, enabling the direct use of the 3D model for individual analyses.

\section{Product disposition analysis and optimisation in the digital environment}

An interactive approach is used in digital designing when optimising the disposition arrangement. This procedure is based on the use of analytical tools, providing software solutions for digital design to evaluate and improve the layout of a production system. Standard analytical tools integrated in software 
applications enable the analysis and evaluation of production disposition from the perspective of material flow effectiveness. These tools include Sankey diagram, D-I diagram, utilisation diagram of transport pathways, utilisation of transport means, evaluation of overall transport performance and transport costs.

\section{Proposed system dynamic verification with use of computer simulation}

When desigining and operating a complex production and logistic system, many problems and risks arise. The whole number of variations and complexity of their evaluation makes the choice for the best solution quite difficult. It is the model and simulation that enables managers to "try" an operation of a proposed production and logistic system. It also enables them to evaluate its optimality based on costs and performance parameters. The meaning of the simulation mainly grows with increasing system complexity. In this case, it is the computer simulation that is the only tool enabling a "look into the future" with high accuracy and a denouncing ability. Computer simulation in the digital design concept represents a significant tool for dynamic verification of proposed production or logistic systems. In the case of the production system model and optimisation, it was a static proposal, working with input parameters, which were defined as having a deterministic quantity, on the other hand, in the case of the computer simulation, the proposed production system 3D model is designed with extra data, considering the production system and its future conditions for the operation in reality. Input system parameters (cycle times, operating times of facilities, failures, wastage rate, etc.) are defined as random variables and the simulation model has extra data, describing rules for access management of material items into the production system, coordination of production, service and logistic activities, systems of production task management, etc. Moreover, simulation experiment outputs are then there to evaluate whether the proposed production system will also achieve target parameters in dynamic and stochastic conditions of real production. It is also there to identify critical points of the production system.

\section{Production system visualisation in virtual reality}

Real visualisation of the designed production system is represented by a 3D model, which could be used in different sectors of reality in the virtual continuum. The production system could be visualised in a purely virtual environment with use of immersive technologies (HMD - Head Mounted Display) or with the use of complex project systems (CAVE - Computer Assisted Virtual Environments). Another possibility of output visualisation is the use of augmented reality, enabling a combination of the real world with virtual objects. For example, this enables us to visualise the proposed production system in a real environment of a production hall.

\section{Production system design methodology in virtual reality}

The use of virtual, as well as mixed and augmented reality in industry and production system design has a significant importance. There are high demands of production process flexibility and implementation rate of changes into production. There can be enormous losses and high costs due to a small mistake made in a badly designed production system. Therefore, virtual reality has an invaluable ability to create future production systems from a very first brick up to the expedition of a final product.

\section{Virtual reality}

The terms virtual reality (VR), augmented reality (AR) and mixed reality (MR) are not well known today. All these types of reality are part of the virtual continuum. The virtual continuum is described as a wide spectrum of real and virtual world combinations (Khan, 2011). There is a mixed reality in between these two wuth augmented reality and augmented virtuality belonging there (Figure 1).

Virtual reality is created completely by a digital environment and a user is involved in this virtual world. The user is able to move, hear sound effects by use of controllers and control some elements. It is the display device that is necessary in order to display and move through the virtual world. This device is attached to the user's head. There are glasses (HTC Vive Pro) used for virtual reality, which can let the user immerse into the virtual world.

\section{Use of virtual reality in the digital design of production systems}

Nowadays new technologies and software possibilities allow testing new things in production design through the virtual environment (Plinta, 2018). The general methodology or procedure for production, assembly and logistic systems in the virtual reality environment (Figure 2) was prepared at the 
Department of Industrial Engineering in Zilina. This methodology includes 4 basic steps, helping to create new software solutions, enabling the designer to create a production system from scratch.

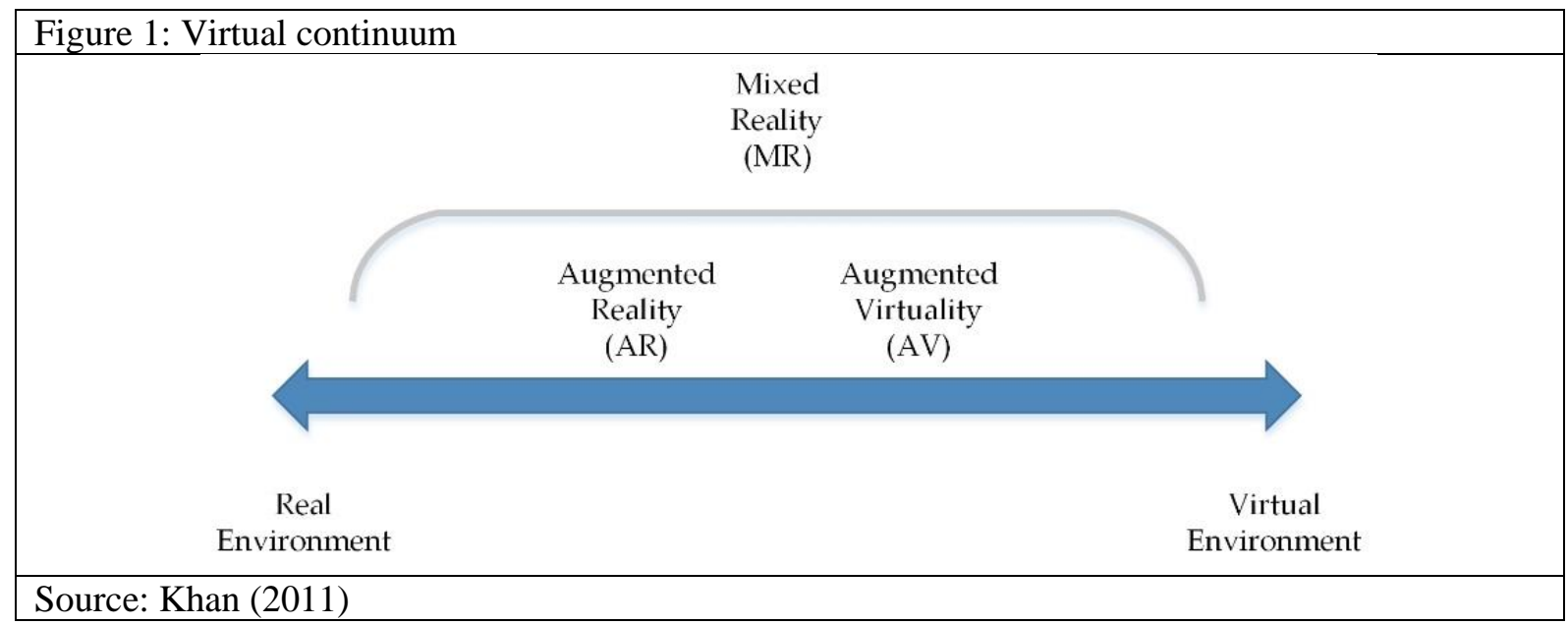

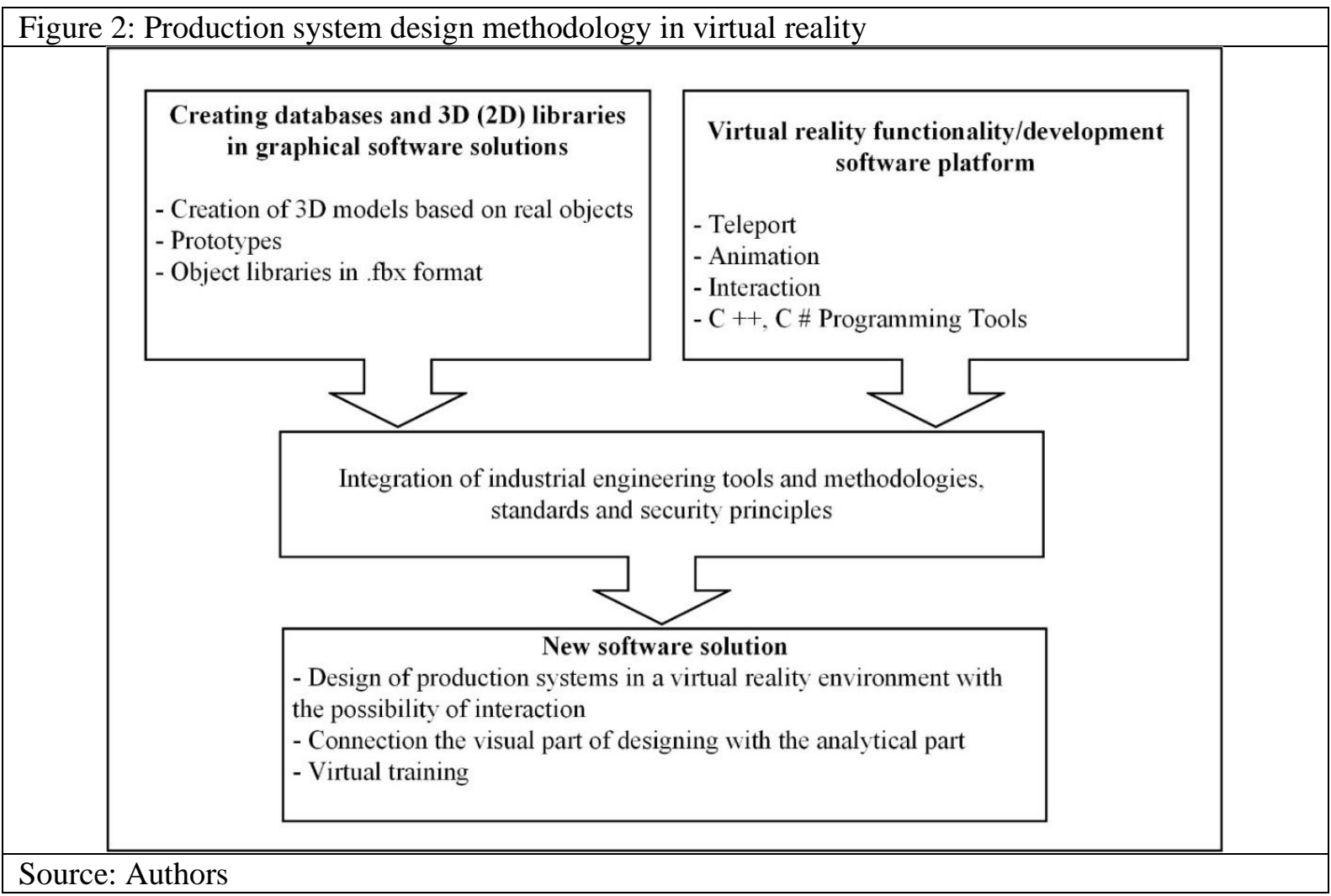

The methodology consists of the three following steps:

Step 1: Database creation of a 2D/3D library - The creation of 3D/2D digital models is the first step in creating a virtual production system. These models represent real production machines, equipment, prototypes, transport and manipulation means used in the production system.

Step 2: Functionality in the virtual display environment - after completing the first step (suitable library creation), a programming library works on developing software platforms. The functionality is tackled through software development via libraries written in a programming language $\mathrm{C}++, \mathrm{C \#}$. It is necessary to point out this environment and programming libraries represent an open system, which contains all functionalities and behaviours of the future system (future applications) purely dependant on the imagination, knowledge and abilities of its designers. Moreover, there is a great advantage if there are animations in the 3D data (e.g. movement of machine parts, material flow - palette movement in production), if objects point out zones of range, service and work and the environment warns them 
about object collision in the case of a wrongly selected distance. This is done to secure the health protection and safety at work.

Step 3: Graphic interface interconnection, the analytical part of industrial engineering with the virtual world - This step includes the integration of the first two steps, in other words, 3D object connection with VR functionality. The important and significant part of this phase is the Industrial Engineering tool, method and technique implementation into the solution itself and "breathing new life" into a static design of a production system in the virtual environment. What it means in reality:

- The selection of production and operational areas around machines, where it is forbidden to place another object due to safety reasons and also due to a possible worker operating there. In case of non-compliance with this condition, the system will visually inform the designer of the object collision.

- The integration with the logistic part of design, e.g. material flow visualisation thanks to the Sankey diagram.

- The selection of worker range zones (ergonomy and work safety), but also manipulative devices (e.g. column-mounted slewing jib crane range). Range zones of workers and production areas near machine tools must be designed according to regulations, designer and ergonomic principles. The job of the industrial engineer is very important here, as he knows these principles and is able to apply them. Therefore, he makes sure every change will be evaluated in real time, and in case of a wrong decision, the mistake can then be corrected.

- The possibility of the selection of an interactive model from a displayed library menu (operated via HTC Vive Pro controllers).

- The coordination system location and gizmo to individual objects, enabling the user to manipulate with them (shift, rotation).

- An information display regarding the work procedure and activities (so-called virtual training), which should be carried out at the particular workplace.

Proposed methodology for verification at the experimental workplace

The proposed design methodology of production systems in virtual reality (Figure 3) was verified by a created workplace in the virtual and augmented reality laboratory at the Department of Industrial Engineering, at the University of Zilina. The result of this proposed methodology and the entire procedure is a virtual production system with an interaction possibility and supportive analytical tools for decision-making. The visualisation is carried out via an HTC Vive Pro. The designer is practically able to use this empty production hall and place production facilities from the library menu. When designing the disposition arrangement, the user is visually notified of possible object collisions, he is aware of workers' range zones (1:1 scale) and therefore he can change his behaviour if necessary. The production or assembly procedure is displayed in selected workplaces and virtual training enables the simulation of work operations and activities from a real system. This way, it is possible to design the entire production system and minimise mistakes made at work, even before construction is implementation.

\section{Conclusion}

This article analyses the application of virtual reality into the digital design process. The methodology does not only include virtual reality for the presentation of final production or logistic systems, but the virtual reality is also applied into the phase of system design itself. The use of virtual or augmented reality technologies helps to improve the quality of the design itself in view of future costs, productivity, safety and environmental friendliness of the future production and logistic system operation. The digital display of a production system in 2D is currently insufficient. By using virtual reality and its tools, a designer has a powerful instrument in his hand taking him into a virtual environment and the designer is then able to work in this environment as in the real world. One of the main advantages of production system design in a virtual reality environment is a great imagination, a realistic chance to detect possible collisions and problems whilst making the production system, and the elimination of procedural errors before the construction itself or when changing the existing situation. Future research in this field could continue with a possible design of production and assembly systems simultaneously by several designers in one virtual environment. Another possibility could be a holonic approach for the integration of information technologies into the production area (Fusko, 2017). Therefore, this is a chance for various 
experts from different fields to cooperate in real time in one real place, even though they would physically be in different locations. They would work online via virtual reality.

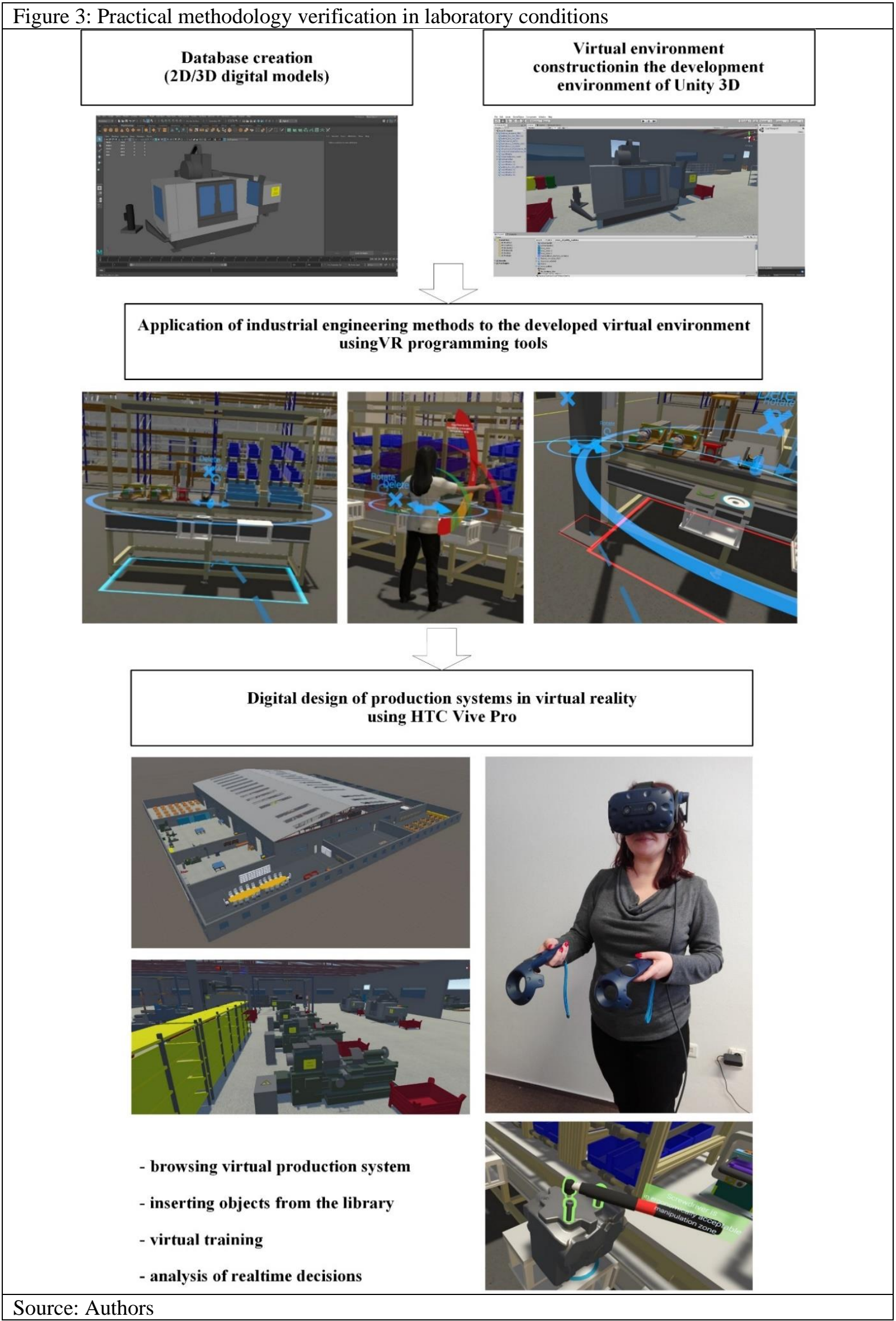




\section{Acknowledgment}

This paper was supported by the research project KEGA 017ŽU-4/2019 - Design of structure and content of the subject Digitalization in industrial engineering for students of the field of technical focus.

\section{References}

Aggteleky, B. (1987). Fabrikplanung: Werksentwicklung und Betriebsrationalisierung. 1: Grundlagen - Zielplanung Vorarbeiten: unternehmerische und systemtechnische Aspekte ; Marketing und Fabrikplanung. München u.a: Hanser. Aggteleky, B. (1990). Fabrikplanung: Werksentwicklung und Betriebsrationalisierung. Bd. 2: Betriebsanalyse und Feasibility-Studie, technisch-wirtschaftliche Optimierung von Anlagen und Bauten. München: Hanser.

Azuma, R. T. (1997). A Survey of Augmented Reality. Presence: Teleoperators and Virtual Environments, 6(4), 355-385. doi:10.1162/pres.1997.6.4.355

Banks, J., Carson, S., L., N. B., D., N. (2005). Discrete-Event System Simulation. Upper Saddle River, NJ: Pearson/Prentice Hall.

Dashchenko, A. I. (2006). Reconfigurable manufacturing systems and transformable factories. Berlin ; New York: Springer. Dulina, L., Bartánusová, M. (2015). CAVE Design Using in Digital Factory. Procedia Engineering, 291-298. doi:10.1016/j.proeng.2015.01.370

Fusko, M., Rakyta, M., Manlig, F. (2017). Reducing of Intralogistics Costs of Spare Parts and Material of Implementation Digitization in Maintenance. Procedia Engineering, 192, 213-218. doi:10.1016/j.proeng.2017.06.037

Gašová, M., Gašo, M., Štefánik, A. (2017). Advanced Industrial Tools of Ergonomics Based on Industry 4.0 Concept. Procedia Engineering, 192, 219-224. doi:10.1016/j.proeng.2017.06.038

Gregor, M., Herčko, J., Grznár, P. (2015). The factory of the future production system research. 201521 st International Conference on Automation and Computing (ICAC) (s. 1-6). Glasgow, United Kingdom: IEEE. doi:10.1109/IConAC.2015.7313998

Gregor, M., Medvecký, Š., Furmann, R. M. (2016). 3D laserové skenovanie vel'kých objektov. Žilina: CEIT.

Gregor, M., Medvecký, Š., Mičieta, B., Matuszek, J., Hrčeková, A. (2006). Digitálny podnik. Žilina: Slovenské centrum produktivity.

Grundig, C.-G. (2006). Fabrikplanung: Planungssystematik - Methoden - Anwendungen. München: Hanser.

Kelton, W. D., Smith, J., Sturrock, D. (2011). Simio and simulation: modeling, analysis, applications. Boston: McGraw Hill, 2 ed.

Khan, W. A., Raouf, A., Cheng, K. (2011). Virtual manufacturing (Springer series in advanced manufacturing. vyd.). London: Springer.

Košturiak, J., Gregor, M., Mičieta, B., Matuszek, J. (2000). Projektovanie výrobných systémov pre 21. storočie. Žilina: EDIS.

Kovalský, M., Mičieta, B. (2017). Support planning and optimization of eintelligent logistics systems. Procedia Engineering, 451-456.

Kühn, W. (2006). Digitale Fabrik: Fabriksimulation für Produktionsplaner. München: Hanser.

Law, A. M. (1999). Simulation of manufacturing systems. Winter Simulation Conference proceedings. New York: Association for Computing Machinery [u.a.].

Law, A. M. (2006). Simulation modeling and analysis. Boston: McGraw-Hill.

Ma, D. (2011). Virtual Reality and Augmented Reality in Industry: The 2nd Sino-German Workshop. Shanghai: Shanghai Jiao Tong University Press.

Mičieta, B., Ďurica, L., Biňasová, V. (2018). New Solution of Abstract Architecture for Control and Coordination Decentralized Systems. Tehnicki vjesnik - Technical Gazette, 135-143. doi:10.17559/TV-20160117100949

Mihelj, M., Novak, D., Beguš, S. (2014). Virtual reality technology and applications (Volume 68. vyd.). Dordrecht [Netherlands]: Springer.

Mleczko, J., Dulina, L. (2014). Manufacturing Documentation for the High-Variety Products. Management and Production Engineering Review, 53-61. doi:DOI 10.2478/mper-2014-0027

Muther, R. (1973). Systematic layout planning. CBI.

Ong, S. K., Nee, A. Y. (2004). Virtual and Augmented reality applicatins in manufacturing. London: Springer Verlag. Pawellek, G. (2008). Ganzheitliche Fabrikplanung: Grundlagen, Vorgehensweise, EDV-Unterstützung. Berlin: Springer. Pegden, C. D., Shannon, R. E., Sadowski, R. P. (1995). Introduction to Simulation Using SIMAN (Second Edition. vyd.). New York: McGraw-Hill.

Plinta, D., Dulina, L. (2018). Ergonomics Analysis in the Context of a Digital Factory. In Z. Wilimowska, L. Borzemski, J. Borzemski, Information Systems Architecture and Technology: Proceedings of 38th International Conference on Information Systems Architecture and Technology - ISAT 2017 (s. 304-313). Cham: Springer International Publishing. doi:DOI: 10.1007/978-3-319-67223-6_29

Schmalstieg, D., Höllerer, T. (2016). Augmented reality: principles and practice. Boston: Addison-Wesley.

Schmigalla, H. (1995). Fabrikplanung: Begriffe und Zusammenhänge. München: Hanser.

Sule, D. R. (2009). Manufacturing facilities: location, planning, and design. Boca Raton: CRC Press.

Wiendahl, H.-P., Reichardt, J., Nyhuis, P. (2009). Handbuch Fabrikplanung: Konzept, Gestaltung und Umsetzung wandlungsfähiger Produktionsstätten. München: Hanser. 